\title{
SUSTAINABLE USE AND PRODUCTION OF ENERGY IN THE 21ST CENTURY
}

\author{
OVE T. GUDMESTAD ${ }^{1} \&$ KJELL TRAA ${ }^{2}$ \\ ${ }^{1}$ Department of Mechanical and Structural Engineering and Material Science, University of Stavanger, Norway. \\ ${ }^{2}$ Kjell Traa Consulting, Norway.
}

\begin{abstract}
It is foreseen that oil and gas will continue to be the key energy sources in the 21 st century. Therefore, it is important that oil and gas be produced in a sustainable way during the next decades. This requires technology development to ensure that the environmental impact and pollution from these activities are minimal. The following aspects are being highlighted in this paper:
\end{abstract}

- Development of projects with the minimum of impact on the environment and problems for local populations.

- Sustainable drilling without the use of oil-based mud, and collection of all drilling waste during offshore drilling operations in the most environmentally sensitive areas.

- Treatment of produced water, sand and minerals from the well stream to avoid pollution.

- Limitation of flaring to be performed only when required for safety reasons.

- Continuous checking of pipelines to ensure that gas pipelines are run within their actual pressure capacity and that oil pipelines are not leaking into rivers and lakes.

- Provision of sufficient storage capacity for gas to ensure timely delivery of gas during high demand peaks.

- Injection of $\mathrm{CO}_{2}$ into sealed underground formations where large quantities are produced, such as at LNG factories.

- Optimization of production from existing fields to avoid huge amounts of oil and gas being left in place, following a 'hit and run' recovery plan.

Furthermore, all primary energy sources need to be converted into end-user energy services known as mechanical work, electricity, heating and cooling. In the process of conversion, only a portion of the primary energy is transformed into the new form, while the rest remains unaltered and is lost.

The various forms of energy services produced represent different values or qualities, e.g. heat holds an energy quality ranging from 0 and upwards, depending on the temperature difference which is utilized, as defined by the second law of thermodynamics. Energy efficiency in this context may also be defined as the ratio between energy quality output and input.

Practically, all fossil fuels are converted into energy services via combustion and heat, i.e. the conversion efficiency is solely determined by temperatures, meaning that high-energy efficiency can only be obtained at large temperature differences, such as in power generation, while ordinary domestic heating will yield a very low efficiency.

Given that some $30-40 \%$ of all fossil fuels today are used for domestic heating, representing an end-user energy quality of (say) $1 / 10$ of what is obtained in modern power generation, there is a large potential globally for energy efficiency improvements, not to mention the associated emission reductions.

The obvious solution is to pay more attention to the second law of thermodynamics, i.e. to shift from direct combustion heating to thermodynamic principles, e.g. by the use of electrical-driven heat pumps and/or combined heat and power as another alternative.

The objectives of this paper are to highlight how energy production could become more effective, thus leading to a reduction in pollution to land, sea and atmosphere and also to identify how energy production should be carried out to minimize the polluting effects. The goal is to provide a reminder that much can be gained with respect to the reduction of pollution by focusing on cleaner energy production. Keywords: efficiency, electricity, energy, environment, flaring, pollution, sustainable oil and gas production 


\section{INTRODUCTION}

The demand for energy has grown to a level where it risks putting our future at stake. Since the industrial revolution more than 100 years ago, the dominating energy supply has come from non-renewable fossil fuels (coal, oil and natural gas), accounting for more than $80 \%$ of total supply, while the remaining demand is covered by hydro, nuclear and renewable energy sources (biofuels, wind power, geothermal heat, solar, tidal power, etc.).

The new trend in today's energy market in Europe, however, is to provide huge subsidies to develop renewable energy sources such as wind and solar energy. Gas is considered as pollutant by some and the suggestion is that it should be phased out, along with nuclear power. There are, however, severe problems with this trend. A stable 24-h-a-day request for energy cannot be provided by the renewable sources. Therefore, coal-fired plants are used for back up. When started up, these plants lead to large amounts of emissions. The fact is that the total amount of emissions in Europe is increasing.

In China, a large number of coal-fired plants are being built, leading to increased amounts of smog in many of the big cities. The pollution is so severe that living in these cities carries a great health risk. As an example, in October 2013, the traffic lights in Harbin had to be shut down, as they were not visible to car drivers $[1,2]$. Winter heating systems fired by coal were blamed, in part, for the crisis.

A root cause to all this is the enormous waste of energy, which is still taking place on earth, despite well-known knowledge, which tells us how to do better. The energy loss is inextricably linked to energy conversion, as illustrated in Fig. 1.

All primary energy sources need to be converted to end-user energy services (such as mechanical work, electricity, heating and cooling), and conversion of primary energies suffer from losses, as well as harmful emissions, for fuels that are converted via combustion. Enduser energy services are ranked according to their quality with electricity at the top of the scale and ordinary domestic heating at the bottom.

Given that some 30-40\% of all fossil fuels today are used for ordinary heating, representing an end-user energy quality of (say) $1 / 0$ of what is obtained in modern power generation, there is a huge potential globally for energy efficiency improvements, not to mention the

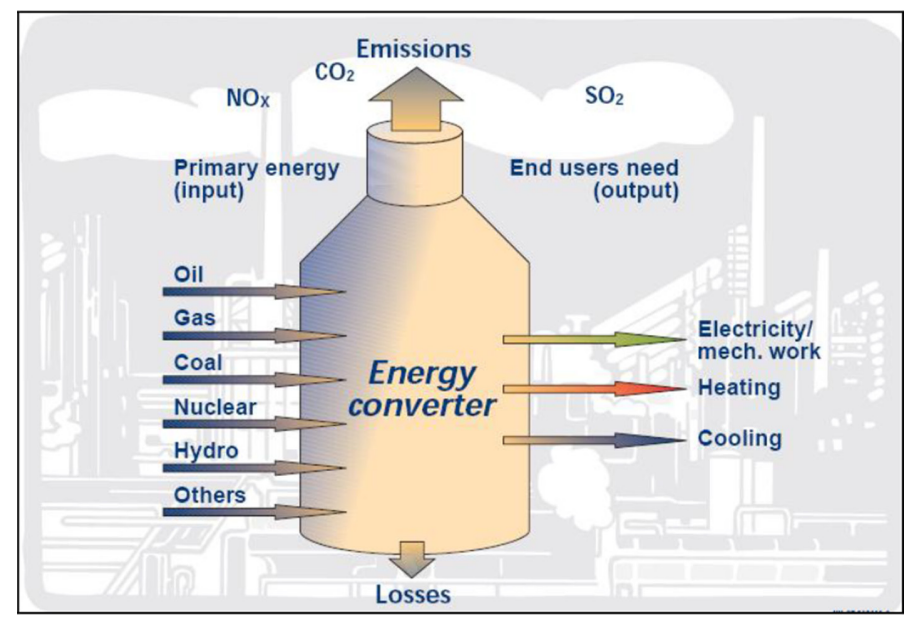

Figure 1: Conversion of primary energies to end-user energy services. 
associated potential emission reductions. Improvements in energy efficiency, therefore, is among the top-ranked measures in several official international/national action plans, to curb the global warming trend, such as EU's 'Energy Roadmap 2050' [3] and the UK 'Carbon Plan 2050' [4].

This also leads us to the use of gas as a stable source of energy, with far less emissions than coal and with a much smaller risk of large accidents than the use of nuclear power. This statement is particularly true when the production and the use of gas are carried out in a sustainable way, where the focus is on the minimization of emission from production and on when the energy is used most efficiently.

In this paper, measures to limit pollution from oil and gas production, how the pollution from the use of gas as energy source can be further minimized and how energy can be produced from gas in the most efficient way will be discussed. Of main concern is the emission of $\mathrm{CO}_{2}$ from the burning of gas and liquid fuels. In the US, there is a drive to limit emissions from power plants and heavy trucks [3], reducing the global warming trend. Some scientists are much concerned that a drastic limitation of $\mathrm{CO}_{2}$ emission is necessary to avoid atmospheric overheating and huge climate changes.

Without a dramatic transfer from the use of coal to the use of gas, reducing the $\mathrm{CO}_{2}$ emissions seems an impossible goal. Therefore, the use of gas produced in a sustainable way will be considered as a key to meeting the emission targets being set by the international community.

In this respect, it should be noted that the average emission rates in the USA from natural gas-fired generation are $1135 \mathrm{lbs} / \mathrm{MWh}$ of carbon dioxide, $0.1 \mathrm{lbs} / \mathrm{MWh}$ of sulfur dioxide and $1.7 \mathrm{lbs} / \mathrm{MWh}$ of nitrogen oxides. On the other hand, the average emissions rates in the USA from coal-fired generation are $2249 \mathrm{lbs} / \mathrm{MWh}$ of carbon dioxide, $13 \mathrm{lbs} / \mathrm{MWh}$ of sulfur dioxide and $6 \mathrm{lbs} / \mathrm{MWh}$ of nitrogen [4]. The traditional direct burning of coal and of coal briquettes, as occurs in Chinese households, accounts for large contributions to the air pollution in China, and such burning exhibits much more pollution than that from coal-fired plants.

There seems to be a need for providing a reminder that much can be gained with respect to reduction of pollution by focusing on cleaner energy production. There seems to be a gap in general knowledge between the requirement for less emission and the knowledge on how to provide reduced emission by optimizing the energy production processes and by highlighting the different processes' potential for the reduction of pollution.

\section{ENERGY DEFINITIONS AND TERMS}

Energy may be defined as 'ability to do work', or as ability or potential to make something happen. Further, energy exists in several forms, such as:

- Chemical energy stored in a substance and which can be released by a chemical reaction (e.g. by burning of a fuel).

- Mechanical energy or electricity (which effectively is a form of work).

- Potential energy (e.g. a water fall or energy stored in a spring).

- Heat, e.g. for heating, melting or evaporating of a substance.

- Light and several more.

As some $90 \%$ of the global energy is derived from conversion to heat, heat-based energy services will be concentrated on the following. Conversion of heat to energy services (such 
as mechanical work, electricity or various heating purposes) is subject to the laws of thermodynamics:

- The first law is about conservation of energy, stating that energy is neither created nor destroyed, but merely changed from one form to another. (Exception to this first law is nuclear reactions only, where matter is converted to energy.) It is quite common to speak about 'energy consumption', but such expression is of course meaningless, since energy cannot be consumed or disappear; it can merely be utilized during its inexorable drop from higher to lower temperature, until it ends up as heat dissipated to the environment (air, water and soil).

- The proportion of energy that can be exploited is defined by the second law of thermodynamics, stating that heat cannot be converted directly into mechanical work (which is one of the several definitions of the second law). The part of an amount of heat energy that may be transformed into mechanical work is determined by the temperatures where the heat is supplied, respectively, and emitted. This is expressed in the following equation, for an ideal loss free process:

$$
\mathrm{W}=\mathrm{Q}(\mathrm{T} 1-\mathrm{T} 2) / \mathrm{T} 1
$$

where $\mathrm{W}$ is the mechanical work obtained, also called 'Exergy', Q is the heat supplied, T1 is the absolute temperature $(K)$ of heat supplied and $T 2$ is the absolute temperature $(K)$ of heat emitted.

When T2 equals ambient temperature, the maximum mechanical work $\left(\mathrm{W}_{\max }\right)$ is obtained. $\mathrm{W}_{\max }$ is then the theoretical maximum amount of useful mechanical work that can be extracted from a given amount of heat. The above equation and expressions related to the second law of thermodynamics are illustrated in Fig. 2.

\section{INTRODUCTION OF THE TERM 'EXERGY'}

As is seen from Fig. 2, energy consists of two elements, according to the equation:

\section{Energy $=$ exergy + anergy}

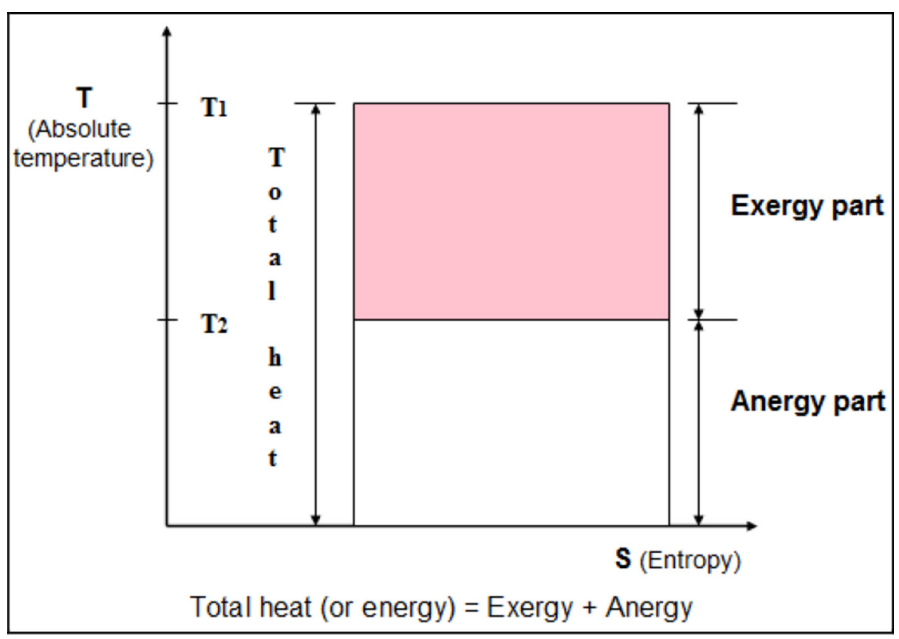

Figure 2: Temperature - entropy diagram for an ideal loss-free process, where heat is supplied/emitted at constant temperature. 'Anergy' = ambient heat. 
Exergy is the part of energy, which is valuable and at the same time is a measure of the quality of an energy service, while the Anergy part makes up the losses and therefore has no value. In contrast to energy in general (which can neither be created nor destroyed), exergy (or energy quality) will be consumed in all energy transformations. When converting heat produced from primary energies, the exergy recovery depends on the temperature drop, which is utilized and this is in principle similar to hydropower, where:

- The water flow (mass) corresponds to the flow of thermal energy (kcal or kWh).

- The water fall height corresponds to the temperature drop in a thermal system.

In both cases, the challenge is to capture as much exergy as possible out of waterfall height, respectively, and the temperature drop in a flow of heat.

The exergy content determines the quality of an energy service, with mechanical work and electricity ranked at the top of the quality scale, both representing practically pure exergy, while the quality of various heating services (steam and other heating measures) depends on the temperature. This is shown in Fig. 3, where $0^{\circ} \mathrm{C}$ is used as the ambient temperature and the exergy content is computed using the second law of equation as explained above.

Looking at the exergy numbers in Fig. 3, it is worthwhile to take note of the following:

- At the upper end: Heat supply at $1200^{\circ} \mathrm{C}$ coincides roughly with today's maximum allowable inlet temperature in modern gas power plants, due to material constraints. Consequently, one way to improve the exergy efficiency (also called the thermal efficiency of a power plant), beyond today's maximum of about $60 \%$ (for large combined cycle power plants, see Figure 4) would be to raise the inlet temperature, and this is likely to happen along with the further development of heat-resistant materials.

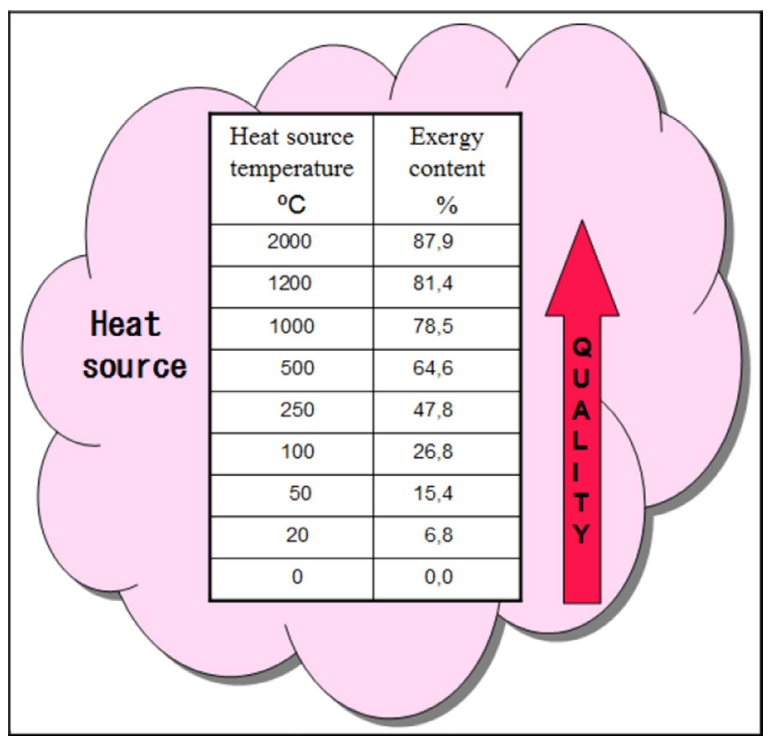

Figure 3: Exergy content of heat as a function of temperature. 
- At the lower end: For ordinary domestic heating with heat supply at $20^{\circ} \mathrm{C}$ room temperature and assuming $0^{\circ} \mathrm{C}$ as outdoor (ambient) temperature, the exergy content is reduced to $6.8 \%$ only. Consequently, when using primary fuels or electricity to provide a low-quality energy service, such as ordinary house heating, a tremendous loss of useful energy is lost.

A main challenge in energy management is to be aware that the degradation of energy quality (i.e. exergy) is permanent and irreversible and is in contrast to energy and the first law of thermodynamics.

In simple terms, it means to adapt the quality of the energy source to the actual service, for minimizing losses and emissions.

\section{ILLUSTRATION OF ENERGY VERSUS EXERGY ACCOUNTS}

Figure 4 shows five different energy applications with related flows of energy and exergy. The various options warrant some further explanations and comments as follows:

Application 1: When burning a fossil fuel, such as oil or gas, for ordinary house heating, a fraction only of the fuel exergy $(100 \%)$ is required to maintain a temperature difference of $20^{\circ}$ (used as example), between indoor and outdoor temperatures. As shown in Fig. 3, the exergy content at $20^{\circ} \mathrm{C}$ is $6.8 \%$ only (theoretical) and may be rounded off to $6 \%$ due to losses, i.e. the final exergy recovery will be $6 \% \times 0.85 \approx 5 \%$.

Application 2: The use of electricity for direct heating is also extremely inefficient, but since all electricity is converted into heat, the exergy recovery at same temperature conditions as in Application 1 is now about 6\%.

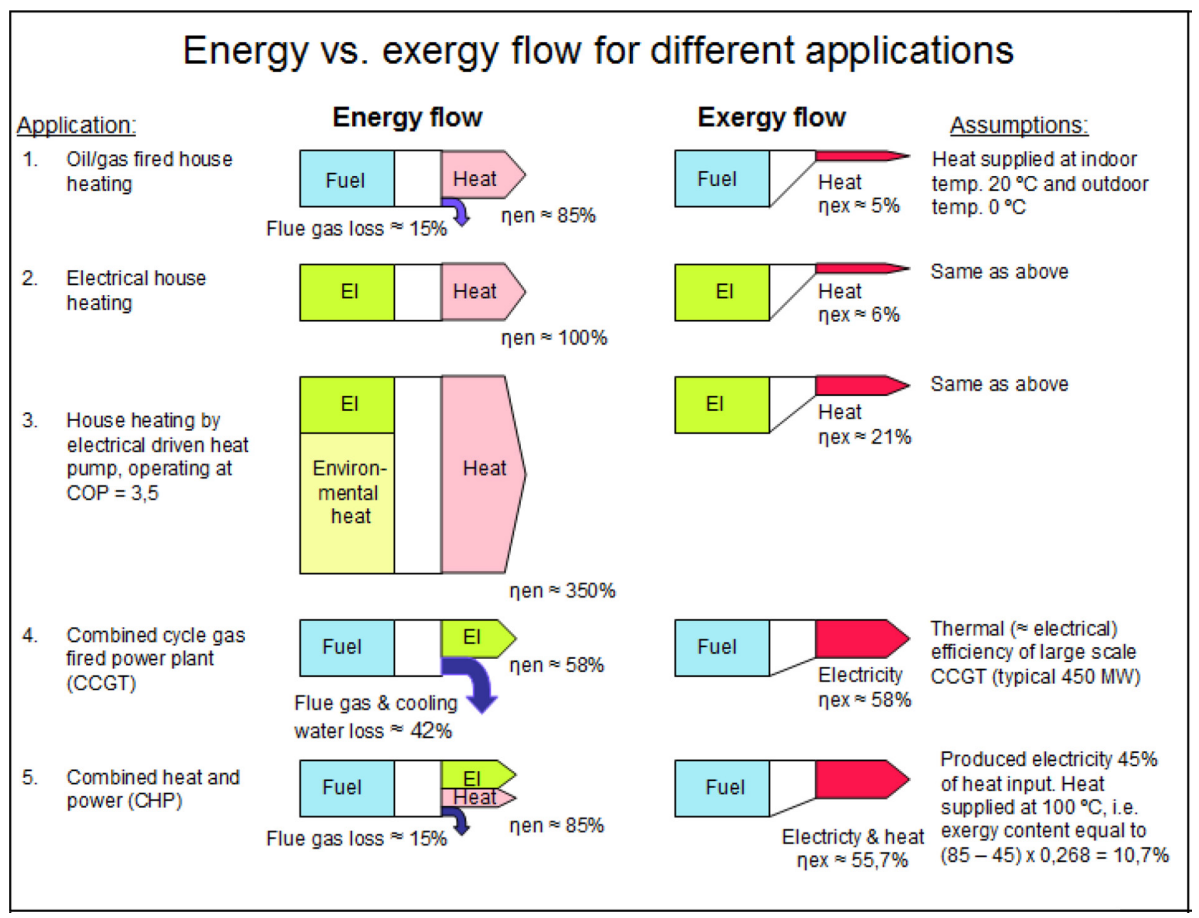

Figure 4: Energy versus exergy flow for different applications, $\eta_{\mathrm{en}}=$ energetic efficiency, $\eta_{\mathrm{ex}}=$ exergetic efficiency. 
Application 3: An electrical-driven heat pump will deliver heat according to its COP (coefficient of performance). In this case with $\mathrm{COP}=3.5$, the exergy recovery will be equal to Application $2 \times 3.5$, i.e. $6 \% \times 3.5=21 \%$.

Application 4: A large modern gas fired combined cycle power plant is able to convert up to about $58 \%$ of the energy supplied into electricity (which is $100 \%$ exergy), depending on climatic conditions (air and cooling water temperatures). The main performance constraint is the temperature at the inlet of the gas turbine, currently limited to $1100-1200^{\circ} \mathrm{C}$, due to material constraints.

Application 5: Combined heat and power (CHP) is an option when there is a stable need for heat (e.g. in the form of hot water or steam), for domestic or industrial purpose close to the plant. The split between power and heat depends on the exact circumstances. By optimization, selecting a split, e.g. as indicated in this example, it is possible to obtain an exergy efficiency comparable to a combined cycle power plant.

\section{MISCONCEPTIONS ABOUT ENERGY AND EFFICIENCY}

There are many misconceptions and errors concerning energy matters, mainly due to lack of knowledge, in today's society. This is most serious, in particular, when decision makers within energy policies and management demonstrate such lack of knowledge.

- Arguing that direct burning of fuel for heat is more energy efficient than power generation. As has been demonstrated above, this is actually turning facts upside down, since conversion to electricity is by far the most efficient way to utilize fuels, while direct firing for domestic heating is the least effective option.

- Arguing that CHP yields higher efficiency than pure power generation, by simply counting units $(\mathrm{kWh})$ of electricity and heat as equal. However, to calculate correctly on an equal basis, it is the exergy content of both services, which needs to be added.

- The indiscriminate use of $\mathrm{kWh}$ as unit in sales of energy, regardless of the quality of the energy source. As an example (published in Norway): The energy content of gas sold in a month is equal to twice the annual Norwegian hydropower production. Obviously, it is a serious misconception to compare directly the calorific value of gas produced with produced hydro-electrical $\mathrm{kWh}$. If such comparison should be meaningful, one had to assume that the gas was first converted to power and assuming an average electrical efficiency of (say) $50 \%$, the answer would be that the Norwegian gas production in 1 month, on equal terms, might be comparable to half of the annual Norwegian hydropower production.

Another frequently used term is energy consumption, but as is known from the first law of thermodynamics, energy cannot be consumed (in the sense that it will disappear); it can only be utilized through conversion. And the overall challenge in all such utilization of energy is to harvest as much of the precious exergy as possible, before it all ends up as anergy (ambient heat).

\section{STRATEGIES FOR EFFICIENT ENERGY HOUSEHOLD}

All future primary energy demand projections point in the same upward direction, indicating a growth of at least one-third over the next 20+ years, as illustrated in Fig. 5. Securing supply to meet such increased demand is in itself a major challenge, but to deal with the increased $\mathrm{CO}_{2}$ emissions is by far the most serious issue. To cope with this situation, there is unfortunately one prescription only: The emissions from hydrocarbon fuels must be brought under control, but this is not easier considering the steep projected increase in global demand of $\mathrm{CO}_{2}$ emitting fuels. 


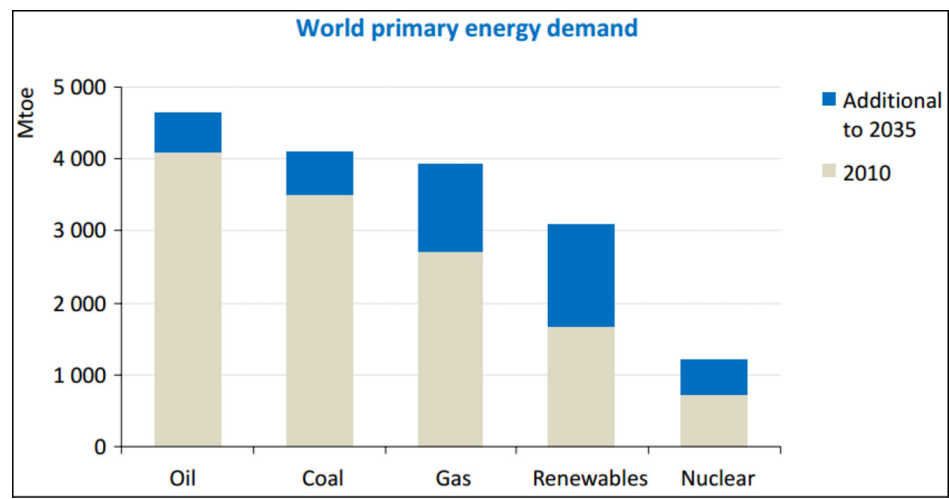

Figure 5: World Energy Outlook 2011 showing primary energy demand increases by onethird between 2010 and 2035 (Source: IEA).

Among the $\mathrm{CO}_{2}$ reducing measures that are wished/planned/researched/available, increased energy efficiency stands out as one of the most realistic and effective measures. Knowledge as well as technologies related to energy efficiency measures are well known, in contrast to emission-reducing measures, such as $\mathrm{CO}_{2}$ removal and sequestration, where technical solutions are still at research and testing levels. It is, therefore, imperative that improvements in energy efficiency are further strengthened and remain as top-ranked measures to curb the galloping negative trend related to energy, emissions and global warming.

Strategies for implementing more efficient use of energy should be based on the following key issues and assumptions:

- Primary energies used directly for ordinary domestic heating represent an enormous waste of exergy and should be replaced by thermodynamic heating principles, e.g. electricaldriven heat pumps and CHP. Potential gains within this segment of energy supply are large, knowing that $30-40 \%$ of all fossil fuels today are used for ordinary low-quality heating services, with an exergy efficiency in the order of 5-6\% only

- An overriding first priority should be to focus on electricity, in conversion of primary energies into end-user energy services, thus securing the highest possible exergy efficiency. It is important to keep in mind that electricity nearly meets all end-user needs (light, mechanical work, heating, cooling, IT services, etc.), except for certain transportation services powered by conventional fuels.

- Because of the above, energy distribution by wire only should be preferred, rather than a double system by parallel installation of a gas distribution grid. In countries where gas distribution is already widespread, priority could be on local CHP, in sizes down to smallscale gas-fired household CHP. Building of new residential gas distribution infrastructure should be rejected. To further improve the exergy recovery in power generation, priority should be on development of materials, which will allow gas turbine inlet temperatures beyond today's maximum of $1100-1200^{\circ} \mathrm{C}$ and thus obtain thermal efficiencies above $60 \%$.

- Similarly, priority should be on further development of 'reversible' heat pumps, suitable for heating as well as refrigeration services, targeting COP (for heating) well beyond today's 3.5-4, up to (say) 5-6, meaning that an exergy efficiency in excess of $30 \%$ for ordinary heating might be obtained. 
- Replace conventional lighting with light-emitting diode lighting, thus obtaining 70-80\% energy saving. Knowing that some $20 \%$ of today's electricity production worldwide is used for lighting, the energy (or more correctly: exergy) saving potential by using lightemitting diode lighting is enormous.

\section{ECONOMICS OF SUSTAINABLE HYDROCARBON DEVELOPMENT PROJECTS}

The economy plays an important role in industry. Decisions regarding projects must be based on economic considerations amongst technically well-developed solutions where technical maturity, safety and clean environment have been considered.

In this context, the word 'sustainable' means that all relevant aspects have been taken into account and that the physical environment is not destroyed by the industrial enterprise. Unfortunately, there are industrialized areas where the industry is not 'sustainable'. Among these are Nikel, a mining city in Northern Russia, close to the Norwegian border, where the emission of sulfur and heavy metals has destroyed the vegetation in a large area around the city. A dead zone of elliptic shape is formed, depending on the wind directions.

In the following discussion, it will be assumed that it is agreed amongst all partners in a project and an operation that the project shall take care of safety and the environment, regardless of whether this is more costly in the short term. If can be argued that 'if one cannot afford safety, one could try the cost and the shame of an accident'. Furthermore, one should notice the huge costs of cleanup operations where the land is destroyed. In this respect, reference could be made to the vast area now out of farming production following the Chernobyl nuclear power plant catastrophe.

Having argued that all projects shall be 'sustainable', this does not necessarily mean that projects will be totally emission free. It will not be possible to produce and use oil and gas without some emission and some pollution. According to US Environmental Protection Agency [5], the amount of $\mathrm{CO}_{2}$ emission is on average 132 tons per 1000 tons of hydrocarbon produced and the amount of $\mathrm{CH}_{4}$ emission per 1000 tons is 1.3 tons. The optimal level of pollution should be selected such that the marginal benefit of reducing pollution just equals the marginal cost. The quantity of contaminants in the air should be below the level of interference with human health, safety and comfort, expressed in parts per million, which conform to approved international standards, see also [6].

\section{METHODS FOR SUSTAINABLE HYDROCARBON PRODUCTION}

There are several sources of pollution and emission from oil and gas production; see Fig. 6 . For hydrocarbon production to be termed 'sustainable', the emission must be reduced to levels permissible by the international society and in agreement with international conventions. As seen from Fig. 6, some of the pollution is to sea and some to air.

In the case of onshore drilling, there is no way to dilute produced water or sewage water by letting the polluted water to flow into the rivers, as a river carries a limited amount of water that easily becomes heavily polluted. Therefore, it will be necessary to collect and treat the polluted water.

\subsection{Drilling with environmentally degradable drilling mud}

Offshore drilling without the use of oil-based mud and with the collection of all drilling waste represents a great environmental benefit. Environmental friendly drilling mud should be biodegradable, and it should be possible to spread the drilling waste on the ground to enrich or 


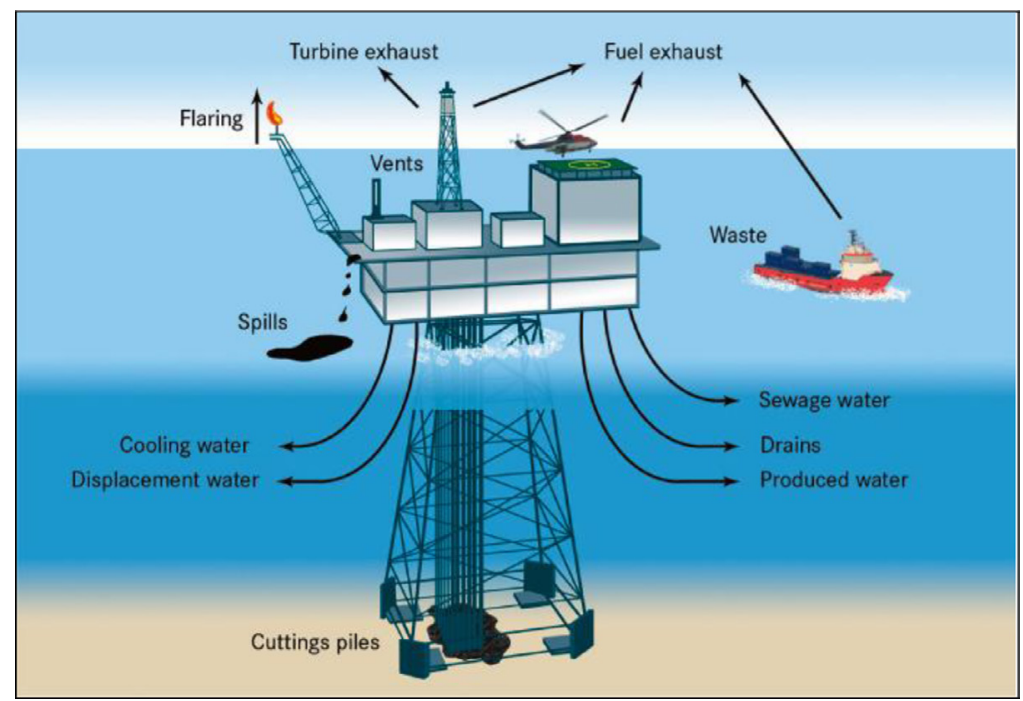

Figure 6: Pollution released from a range of sources during routine offshore oil and gas production [7]. It should, however, be noted that most of this pollution is taken care of during routine operations.

rehabilitate the soil. Offshore drilling in the North Sea primarily uses water-based mud with non-lethal additives.

\subsection{Treatment of well stream products}

The well stream will normally contain greenhouse gases such as $\mathrm{CH}_{4}$ (methane) and other hydrocarbon gas components as well as water or traces of water, $\mathrm{CO}_{2}$ and or $\mathrm{H}_{2} \mathrm{~S}$, sand and heavy metals, and, in some cases, radioactive compounds. It is, therefore, a requirement that the well stream is treated in such a way that the sales products, the gas and the liquid components, are free from detrimental elements. When doing so, sufficient attention must be paid to the storage of the waste to avoid it causing a risk to health or polluting the environment.

Of particular concern are toxic gases, such as $\mathrm{H}_{2} \mathrm{~S}$, in particular when causing a pile-up of large accumulations of sulfur, as in the Caspian region, after processing the gas. Such piles of sulfur must be covered to avoid the spread of the toxic waste in wind. Of even larger concern is radioactive waste (normally low radioactivity), which must be handled with extreme care to avoid it is being spread amongst the population.

\subsection{Treatment of produced water}

Some oil and gas fields produce large quantities of water. This water is contaminated by the hydrocarbon particles and has to be cleaned before it can be released into the environment, for example, to a river or a lake. In many situations, the river or lake cannot self-clean the remaining hydrocarbons, even if the concentration of hydrocarbon molecules is as low as some few parts per million. Furthermore, heavy metals diluted in the water may have even greater polluting effects than hydrocarbons. Dams have been created to purify polluted 
waters; however, heavy rain may break the containment or the dam could dry out, leaving toxic dust to blow into the air. Recently, bacteria have been used to purify polluted water and this trend is expected to continue in the future.

An alternative will, of course, be to inject the pollutants into the underground, potentially as a driving fluid for increased oil production or more likely into separate permeable rock formations that are sealed, avoiding the injected pollutants returning to the surface or back into the hydrocarbon reservoir.

\subsection{Limitation of flaring to safety issues only}

Flaring of natural gas, as an unwanted byproduct of petroleum production, is a major challenge. Worldwide it is estimated that about 150 billion cubic meters are 'flared' in this manner each year, contributing to several hundreds of millions of tons of carbon dioxide into the atmosphere [8]. Several programs to avoid flaring are being implemented. These consist of gas collection for local heating, gas injection into separate reservoirs or gas injection into the gas cap of an oil reservoir to increase the oil production. The World Bank will deny loans to new developments based on gas flaring or the venting of excess gas, and some governments (including the Norwegian government) are becoming aware of flaring as bad practice and are imposing a tax on all flaring as well as on combustion gases from field facilities. The costs of these measures may be far smaller than the damage greenhouse gases could cause to the environment.

\subsection{Continuous checking of production equipment for leakages}

Every year, leakages from production equipment or transport facilities cause severe damage to the environment. In some places, as in the Niger Delta, the pollution is so severe that people's lives are at stake; access to clean water is difficult and pollution is found almost everywhere in the swampland. Associated gas is often burned, increasing the pollution effect.

It should be noted that river crossings are particularly exposed to pipeline leakages, as the riverbanks will be eroded by the flow of the water in the river. The erosion is strongest in areas of permafrost, as warm river water will melt the shore permafrost and cause quicker erosion compared with rivers with more stable soil along established riverbanks. Therefore, in cold climate regions, the potential for pipeline overstressing and leakages must be considered in the design stage when planning the transport infrastructure from the field.

It should also be noted that pipelines placed on slopes are vulnerable to slope movements and failures and that rain during warm summers is likely to cause failures of such sloping areas. Continuous checking is necessary to ensure the integrity of onshore pipelines and their valves.

\subsection{Availability of gas storage volumes}

The preparation of sufficient storage capacity for gas to ensure timely deliverability during high demand peaks is an important strategy to ensure that customers are satisfied with the reliability of the gas delivery. Gassco is the technical operator of the Norwegian gas transportation system where Statoil previously played a central role in establishing the system. The system consisting of $7925 \mathrm{~km}$ pipelines is integrated into the European gas network with access points in Scotland, Germany, Belgium, France and England. 
In 2007, a new pipeline connected Norway with southern England to transport gas from the Ormen Lange field. Delivery regularity and operating flexibility are important parameters. Therefore, the importance of gas storage has increased. There are three conceptual gas storage business models: sale of storage capacity, enhanced supply and trading. To meet its storage requirements, the Norwegian gas pipeline transportation system includes two storage projects - located in Aldbrough (UK) and Etzel (Germany) (Fig. 7) [9].

\subsection{Injection of $\mathrm{CO}_{2}$ into the ground}

The injection of $\mathrm{CO}_{2}$ into the ground where large quantities of $\mathrm{CO}_{2}$ are extracted (such as at production facilities or at LNG factories) is considered by some to represent the key measure to the reduction of greenhouse gas release into the atmosphere from the oil and gas industry.

$\mathrm{CO}_{2}$ capture is performed at Statoil's Sleipner field by a conventional amine process. It was a challenge to design this process to be sufficiently compact to be placed on an offshore platform in the middle of the North Sea, $250 \mathrm{~km}$ from land.

In 1990, the Statoil-operated gas/condensate field Sleipner Vest in the North Sea was in its planning phase. The natural gas at the Sleipner Vest field initially contains around $9 \% \mathrm{CO}_{2}$, which was too much with respect to customer requirements. The $\mathrm{CO}_{2}$ needed to be removed first.

Furthermore, in 1991, the Norwegian authorities introduced a $\mathrm{CO}_{2}$ offshore tax with the aim of reducing $\mathrm{CO}_{2}$ emissions. Statoil then decided to remove the offshore $\mathrm{CO}_{2}$ and inject it into a deep geological layer below the Sleipner platform (Fig. 8). This layer contains porous sand rock filled with salt water, and is called the Utsira formation. The $\mathrm{CO}_{2}$ is prevented from seeping into the atmosphere by an 800-m thick gastight cap rock above this layer. Its implementation meant a reduction in $\mathrm{CO}_{2}$ emissions of nearly one million tons per year, which was roughly $3 \%$ of the Norwegian $\mathrm{CO}_{2}$ emissions in 1990 . The Sleipner field became operative in October 1996 [10].

\subsection{Optimization of production from existing wells and existing fields}

It is important that large quantities of oil and gas are not left in the reservoir to prevent the operator from adapting a 'hit and run' development scheme, where only the most easily

\section{Etzel Gas Storage}

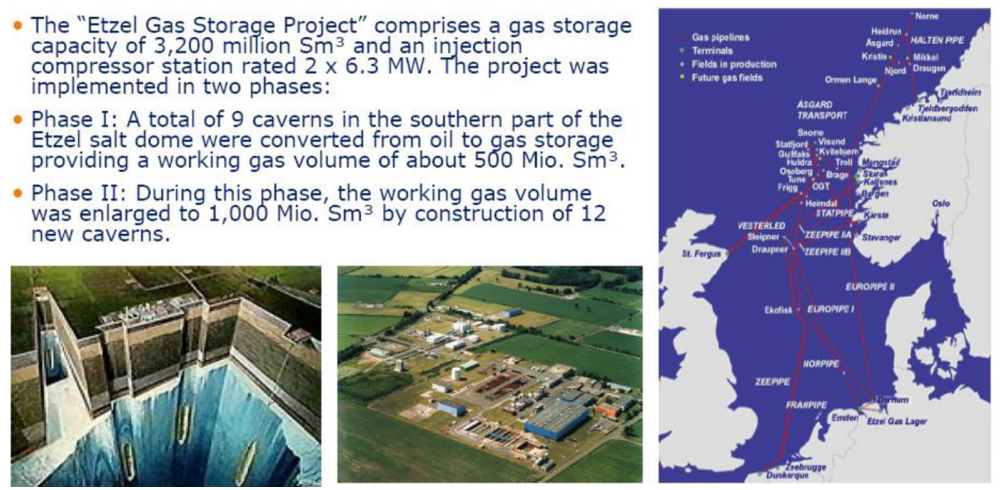

Figure 7: Specifics of the Etzel Gas Storage Facilities [10]. 


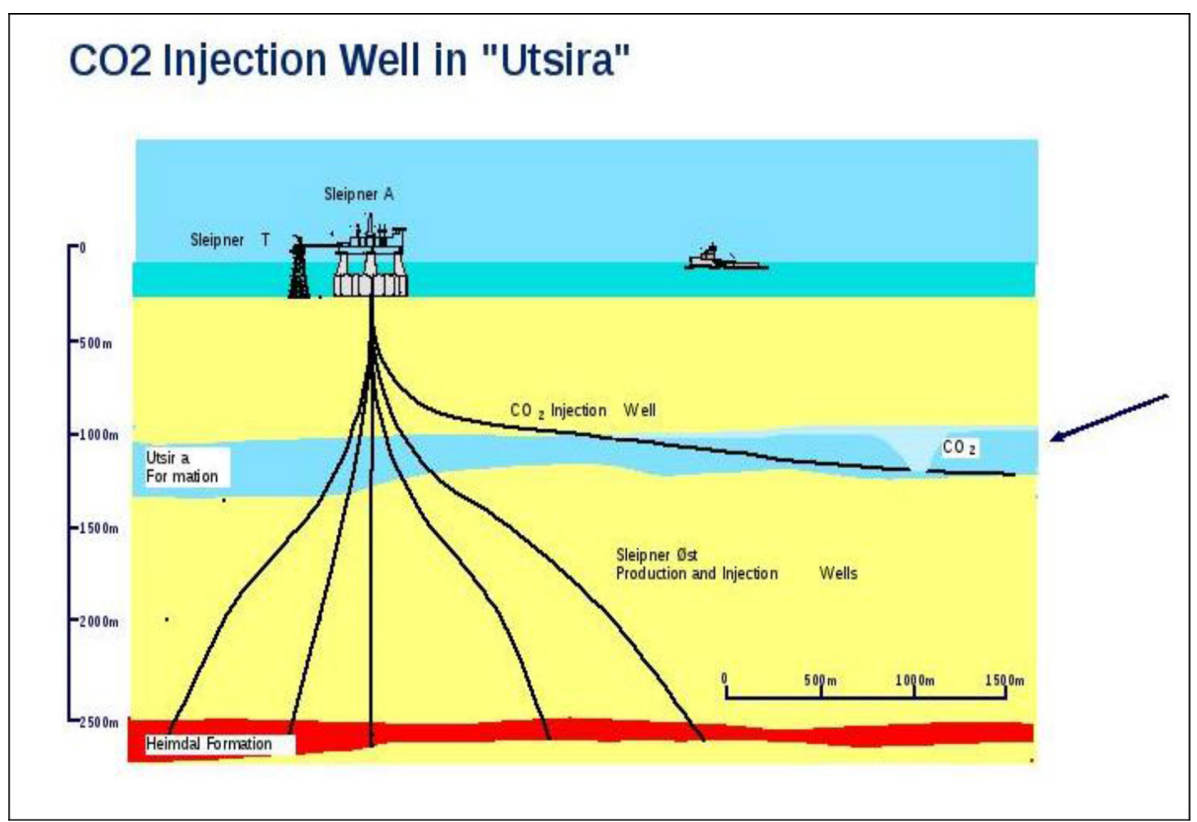

Figure 8: Injection of $\mathrm{CO}_{2}$ into the Utsira geological formation from Statoil's Sleipner field.

accessible oil is produced. The present worldwide oil recovery factor is just above $29 \%$. Furthermore, the worldwide amount of produced hydrocarbons today exceeds the results of exploration. The stock value of companies depends greatly on the recoverable oil to which the companies have access. Secondary and tertiary recovery methods, drilling of additional wells, artificial lift and upgrading of surface facilities provide for improved oil recovery (IOR) and should be implemented in the volumes available to be produced [11].

Some years ago, Statoil prepared a model for future IOR additions worldwide. A weighted final recovery factor of $38 \%$ was estimated, corresponding to $700 \mathrm{~B}$ barrels additional production. IOR, however, poses many technical challenges and good planning is essential. It should also be noticed that the term EOR (Fig. 9) represents enhanced oil recovery, indicating production of oil that normally would not be produced, thus differing from IOR, oil that can be produced with traditional means.

\section{CONCLUSIONS}

The massive waste of energy, which is taking place worldwide needs to be reduced, to reduce the alarming negative consequences, notably the emissions of $\mathrm{CO}_{2}$ from fossil fuels, causing global warming.

As has been demonstrated in this paper, the potential for fuel saving because of increased energy efficiency is formidable and it is therefore not surprising that this measure alone is among the top ranked priorities in the climate debate.

The benefits of fuel saving are obvious, but realizing its full potential (which really is needed to meet the current climate targets), also means reduced energy demand. In today's world, the recipe for successful industrial and economic progress is to stay on an upward trend, but for the energy industry in a sustainable future development, it would have to mean that the trend curve would stagnate and then bend downwards. 


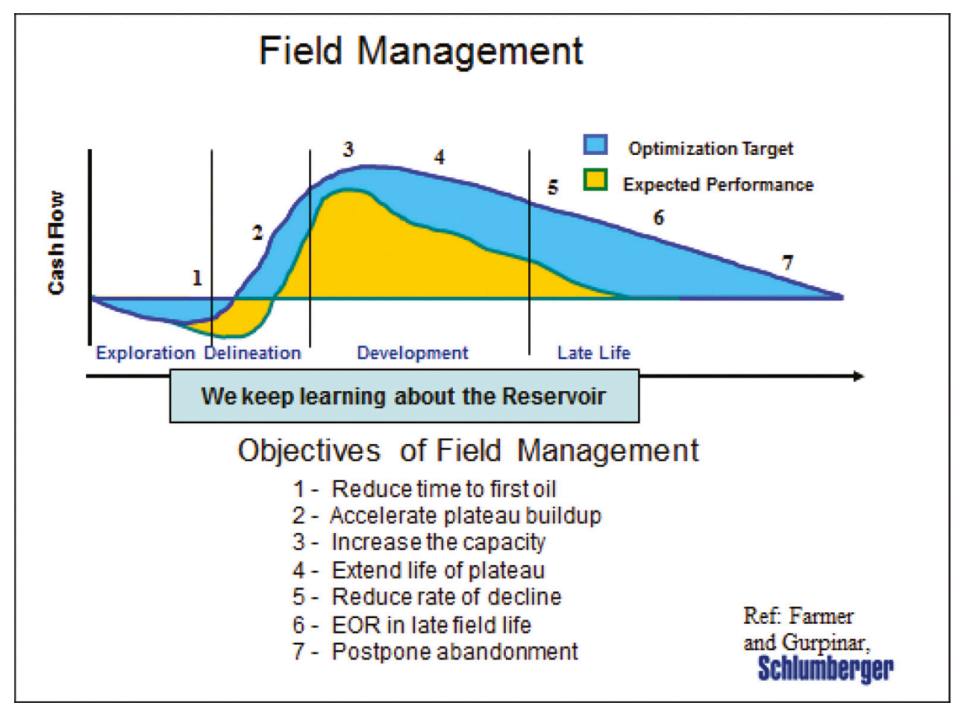

Figure 9: Field management incorporating increased oil recovery [11].

Adding all of the opportunities for energy efficiency improvement together, it will make a significant contribution to energy conservation and emissions reductions. As example: EU has put up as target to increase the overall energy efficiency by $40 \%$ by 2030 . However, implementations of energy efficiency measures are in general slow, despite the fact that knowledge and technology have been known for a very long time. A main cause for the slow progress is lack of basic knowledge among a majority of energy officials and decision makers.

In addition, for sustainable use of fossil energy, clean production processes must be implemented. In this respect, it is suggested that:

- 'Sustainable oil and gas production' should become mandatory in all future petroleum field operations.

- An emerging trend where renewable power is backed up by coal-fired plants, which emit more than double the amount of greenhouse gases per MWh into the atmosphere, as compared with the use of gas needs to be reconsidered.

- In order to term oil and gas production as 'sustainable', efforts must be made to ensure that hydrocarbon fuels are produced and utilized with a minimum of environmental impact.

Implications for policy makers are obvious: Focusing on sustainable energy production as discussed in this paper, the need for dramatic changes in comfort and economic developments may not be necessary. Great reductions in polluting emission can be obtained with reasonable investments. Research should be conducted by societal scientists on how the implementation of sustainable energy production could be adapted by the public and by the politicians.

\section{ACKNOWLEDGEMENTS}

This paper has been prepared as a summary of papers presented by Traa [12] and Gudmestad [13] at conferences arranged by WIT. 


\section{REFERENCES}

[1] http://news.nationalgeographic.com/news/energy/2013/10/131022-harbin-ice-citysmog-crisis-china-coal/, accessed on 30 November 2013.

[2] http://www.telegraph.co.uk/news/worldnews/asia/china/10396198/Chinese-city-ofHarbin-shrouded-in-smog-as-air-pollution-soars.html, accessed on 30 November 2013.

[3] On 15 December 2011, the European Commission adopted the Communication 'Energy Roadmap 2050', whereby the EU is committed to reducing greenhouse gas emissions to $80-95 \%$ below 1990 levels by 2050 , in the context of necessary reductions by developed countries as a group.

[4] The UK Carbon Plan, published in December 2011, sets out the Government's plans for achieving the emissions reductions committed to in the first four carbon budgets, on a pathway consistent with meeting the 2050 target.

[5] United States Environmental Protection Agency. Clean energy, air emissions. http:// www.epa.gov/cleanenergy/energy-and-you/affect/air-emissions.html, accessed on 30 November 2013.

[6] OGP, Environmental performance indicators - 2012 data. OGP, London, Report No. 2012e, November 2013. http://www.ogp.org.uk/pubs/2012e.pdf

[7] Ospar Commission, Quality Status Report, Chapter 7, 2010. http://qsr2010.ospar.org/ en/ch07_01.html.

[8] IPIECA and OGP, Preparing effective flare management plans. Guidance document for the oil and gas industry, OGP Report No. 467, IPIECA and OGP, London, 2011, http:// www.ogp.org.uk/pubs/467.pdf.

[9] Chamanski, A., Statoil experience with UGS, The International Conference "Underground Gas Storage: Sustainability and Efficiency" ("UGS-2006”), 11-13 October 2006, Moscow, Russia.

[10] Statoil, Sleipner Vest, From Statoil's homepage: http://www.statoil.com/en/technologyinnovation/protectingtheenvironment/carboncaptureandstorage/pages/carbondioxideinjectionsleipnervest.aspx

[11] Farmer, C.L. \& Gurpinar, O. Evaluation of field management systems, IPAM, University of California, L.A. Schlumberger presentation top Industrial Problems Study Group, September, 2003, http://www.ipam.ucla.edu/programs/invip/.

[12] Traa, K., Efficient use of energy, Proceedings of "Petroleum 2012", WIT Transactions in Engineering Sciences, 81, pp. 1-14, 2012. ISBN: 978-1-84564-758-2, Edited by F.M Khoshnaw, Koya University, Kurdistan, December 2012.

[13] Gudmestad, O.T. Sustainable oil and gas production in the 21 st century with emphasis on offshore fields, Energy and Management in the 21st century, Proceedings of Energy Quest 2014, Ekaterinburg, Russia. WIT Transactions on Ecology and the Environment, 190, pp. 777-788, 2014, ISSN 1743-3541. doi: http://dx.doi.org/10.2495/eq140722 